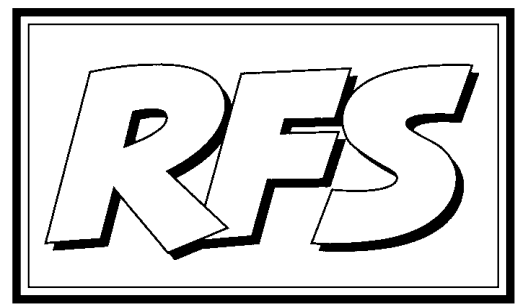

Revista de Fomento Social, 53 (1998), 153-176

\title{
Reparto del tiempo de trabajo y lucha contra el desempleo
}

El paro reviste una gravedad especial en los países industrializados de Europa, y más en particular en España. Esta es la razón que nos hace volver sobre la lucha contra el desempleo, aunque ya la abordamos en estas mismas páginas no hace mucho tiempo (1). Sin embargo ahora nos hemos propuesto hacerlo, no en toda su complejidad, sino fijándonos en un aspecto especialmente debatido en estos meses: el reparto de trabajo. La propuesta francesa de la semana de 35 horas ha suscitado innumerables e inevitables reacciones, variadas en sus enfoques y no siempre libres de pasión. ¿Seríamos capaces nosotros en estas páginas de analizar una cuestión tan peliaguda con una cierta dosis de desapasionamiento, ya que la total objetividad es casi imposible? Ese ha sido nuestro propósito. El

(1) «El empleo en España», Revista de Fomento Social, $n^{o} .194$ (abril-junio 1994), pp. 171-192. 
lector juzgará si nos acompañó el éxito. En todo caso, esperamos contribuir a un debate que es inevitable.

\section{El problema del empleo en general como marco}

Para algunos el paro no es un problema mundial, sino propio de Europa occidental. Es difícil aceptar esta afirmación sin más, cuando sabemos que son muchos los países del planeta en que la falta generalizada de un trabajo remunerado es una de las causas de la pobreza y el subdesarrollo. Pero sí es cierto que entre nosotros el desempleo crónico de estas últimas décadas tiene especiales connotaciones porque sucede a una etapa en que el sistema socioeconómico funcionó sobre el presupuesto del pleno empleo como objetivo siempre alcanzable. Es más, esta circunstancia ha configurado toda una forma de entender y organizar la vida, que está en la base de nuestras sociedades de bienestar.

Efectivamente en Europa, y más en concreto en la Unión Europea (en adelante, UE), la preocupación es grande y ha sido objeto de consideración en momentos cruciales de la construcción europea en estos últimos años.

No nos detendremos en las propuestas del Libro Blanco del Empleo, elaborado bajo la presidencia de Jacques Delors. Más recientemente fue el Tratado de Amsterdam el que representó un cambio de estrategia de la UE, al vincular la política económica al programa en favor del empleo. Este nuevo tratado presenta dicho asunto como un tema de interés común, insistiendo en la necesidad de una actuación conjunta y coordinada y proponiendo que se tenga en consideración el objetivo de un alto nivel de empleo a la hora de formular y aplicar las políticas y actividades comunitarias. Es evidente que tras esta propuesta, late el convencimiento de que el crecimiento económico no basta para acabar con el paro.

Los países de la UE no han esperado a la ratificación de dicho tratado, un proceso, por cierto, laborioso, para enfrentarse de forma conjunta al problema en una Cumbre Especial sobre el Empleo, celebrada el pasado mes de noviembre en Luxemburgo. Fruto de esta Cumbre fue un acuerdo, en el que los Estados miembros se comprometían a combatir el desempleo juvenil y prevenir el desempleo de larga duración; otros compromisos del acuerdo se orientaban a desarrollar el espíritu de empresa, fomentar la 
capacidad de adaptación de los trabajadores y de las empresas y reforzar la política de igualdad de oportunidades. Para conseguir el primero de estos objetivos, los gobiernos debían elaborar, en un plazo no superior a cinco años, planes preventivos con medidas en una doble dirección: ofrecer a los jóvenes una nueva oportunidad antes de haber pasado seis meses en paro, y ofrecer a los desempleados adultos la posibilidad de un nuevo comienzo antes de que hubiesen pasado doce meses en paro.

Sabemos que España se resistió a suscribir el acuerdo, alegando que nuestras tasas de desempleo no eran comparables a las del resto de los países europeos, y por tanto el coste de las medidas tampoco. Finalmente logró la introducción de una cláusula que permite la ampliación del plazo «en los Estados miembros que tengan una tasa de desempleo particularmente elevada». Pero sí ha hecho frente ya al compromiso de la Cumbre de Luxemburgo y ha presentado un Plan de Empleo, que fue aprobado el pasado 3 de abril. Dicho Plan, que centra sus esfuerzos en las reducciones fiscales a las empresas y la reducción de los costes no salariales, no ha sido del agrado de los sindicatos, aunque parece que ha encontrado buena acogida en los medios comunitarios.

Los medios gubernamentales han subrayado los valores de este Plan de Empleo en la preparación de la más recientes de las cumbres europeas, la de Cardiff (16 de junio pasado). Pero parece que en esta ocasión los resultados han sido escasos y la atención se ha centrado casi exclusivamente en el eterno tema de la subsidiariedad, utilizada ahora para propiciar un cierto giro nacionalista.

En todo caso bastan unas cifras para dar una idea de la gravedad del problema, aunque durante los últimos meses la evolución está siendo favorable. Si tomamos como referencia los últimos datos disponibles de la Encuesta de Población Activa a la hora de escribir el presente texto, la tasa de desempleo en España afecta a algo más del 19\% de la población económicamente activa, siendo particularmente sangrante la situación de los jóvenes menores de 25 años, donde el volumen de paro ronda el 40\% de la población activa. En estos datos quedaba asimismo de manifiesto el significativo desfase existente entre el desempleo masculino $(14,24 \%$, con un descenso significativo a partir de los 25 años) y el femenino (26,81\%, concentrado fundamentalmente en las menores de 25 años, aunque con 
una franja también importante, superior al 25\%, para las mayores de esta edad). A esta situación se une en nuestro país el elevado índice de temporalidad, es decir, la precariedad en el empleo: más del 33\% de los trabajadores tenían en 1997 un contrato de duración determinada, mientras que en el caso de las trabajadoras la proporción ascendía casi al 40\%. La UE en su conjunto tenía en abril una tasa de paro del 10,2\% de la población activa, lo que representa un total de 18 millones de personas. El índice de desempleo entre menores de 25 años conoció en abril su nivel más bajo desde 1993 (19,8\%). Como se ha indicado, España sigue teniendo el índice más elevado. Por debajo del 5\% se encuentran Dinamarca, Holanda, Austria y Luxemburgo.

La gravedad del paro radica no sólo en sus dimensiones cuantitativas, sino sobre todo en esa persistencia que lo hace del todo ajeno a un fenómeno coyuntural. Por esta doble causa la lucha contra el paro, si quiere estar a tono con las características del problema, ha de ser diversificada y radical: diversificada, porque un fenómeno tan complejo no puede ser atacado por un solo flanco, sino desde una pluralidad de estrategias convergentes; radical, porque debe ser creativa e innovadora en sus propuestas, sin pretender aferrarse a toda costa a los modelos de estructuración y organización del trabajo que nos ha legado el pasado reciente.

A ambas características responde el reparto del trabajo. En este sentido, nos alegramos que sea hoy objeto de propuestas y debates. Sólo debería excluirse desde ahora la idea de que el reparto de trabajo es la solución, como el talismán que va a acabar por fin con el desempleo. En nuestra opinión, sólo puede considerarse como una de las posibles estrategias, cuya eficacia dependerá en parte del marco global de política económica en que se inserte.

Al tomar parte en este debate somos conscientes también de que, no ya la lucha contra el desempleo en general, sino particularmente el reparto de trabajo, será tema obligado en las campañas electorales que se avecinan. ¡Ojalá no se caiga en una mera instrumentalización política y electoral de este proyecto! Si eso ocurriera, se impediría una discusión ponderada que pueda redundar en resultados beneficiosos, no para los políticos en campaña, sino para los que son víctimas de la falta crónica de empleo. 
Como hemos indicado, la lucha contra el paro ha de ser diversificada; en este sentido, no hay que olvidar que el acento se ha colocado en otras políticas o decisiones más que en el reparto del trabajo.

Así, en Estados Unidos la política de empleo ha seguido una línea neoliberal, en la que la flexibilidad y la desregulación han sido aspectos importantes. No está de más recordar que en USA los niveles de paro no alcanzan los elevados porcentajes europeos pese a la baja «calidad» de una gran proporción de empleos.

En la UE se ha enfocado el problema desde distintos ángulos; además de las medidas flexibilizadoras, ya indicadas en el párrafo anterior, se ha insistido en otras políticas de estructura orientadas a la mejora de la competitividad de la empresa desde un punto de vista tecnológico, desde una mejora de las comunicaciones etc. Recientemente, las políticas de empleo activas han pasado a ocupar un lugar importante en la estrategia de la UE y de sus estados miembros.

En la economía actual, la solución de este problema no puede venir sólo de las políticas públicas, sino que gran parte de las acciones son resultado de acuerdos a dos bandas: sindicatos y organizaciones empresariales o a tres bandas cuando a éstos se les une el propio gobierno. Por último, el protagonismo corresponde a la empresa que es la que tiene que tomar las decisiones día a día; la aplicación de la lucha contra el desempleo tiene que venir de la empresa en el marco de las decisiones macroeconómicas.

Según países y según, también, las distintas opciones políticas, sindicales, sociales etc., el reparto del tiempo de trabajo tiene un papel importante o secundario en este conjunto, pero en todo caso no puede considerarse como una solución única frente al grave problema del paro.

\section{El reparto del tiempo de trabajo en la lucha contra el desempleo}

1. El reparto de trabajo y sus formas

Ya en 1978 la Comisión de Comunidades Europeas concretaba lo que se entendía por reparto de trabajo, así como el sentido que se le daba:

«El objetivo del reparto de trabajo consiste en redistribuir el 
volumen total de trabajo existente en la economía con miras a incrementar las oportunidades de empleo para todas las personas que deseen trabajar. Esto no quiere decir que el volumen de trabajo permanezca constante; más bien se funda en la observación de que ese volumen es en estos momentos insuficiente y de que debemos intentar redistribuirlo»(2).

Esta definición resultaría una evidencia si no subrayara su estrecha relación con la redistribución. No estamos ante una afirmación técnica, sino ante la formulación de un objetivo de política económica, el cual está marcado por un imperativo de justicia y de solidaridad. Se trata de la justicia distributiva, de redistribuir el trabajo entre la población a fin de reducir la magnitud del desempleo involuntario: estamos, pues, ante otra forma de hacer frente con los recursos de todos a las necesidades de todos. $Y$ cuando los recursos son escasos (como es el caso del trabajo), se impone la necesidad de su redistribución. Si el discurso sobre redistribución de la renta resulta más familiar, aplicar la idea de redistribuir al trabajo resulta a algunos chocante: sin embargo cada vez se impone más, como consecuencia de una situación nueva en que el trabajo ha dejado de ser un bien abundante.

Pero no basta con la justicia y la solidaridad. Muchos de los que se oponen al reparto de trabajo aducen que tal medida no contribuiría a reducir el desempleo. Las razones de este escepticismo las analizaremos más adelante. Pero desde ahora queremos dejar sentado que no basta la buena intención, si luego no se llega a alcanzar lo que se pretendía. Con otras palabras, no podemos contentarnos con una ética de la convicción, hemos de aspirar a una ética de la responsabilidad. Y ello nos obliga a analizar con la mayor atención posible si el reparto de trabajo va a tener efectos positivos sobre el nivel general de empleo y en qué condiciones.

Pero son diferentes las fórmulas propuestas para repartir el trabajo. La más común, precisamente la que está en la base de las propuestas que hemos enumerado antes, es la reducción del tiempo de trabajo. A ella le dedicaremos una atención más detenida en el apartado siguiente. Pero hay

(2) Cf. Work sharing. Objetives and Effects. Commission Staff Paper, Bruselas 1978. 
otras que recorreremos con más brevedad posteriormente. Tanto aquélla primera como éstas las hemos seleccionado por su eventual incidencia sobre la ocupación total y la creación de empleo. Pero desde ahora conviene aclarar que prácticamente ninguna de ellas nació con este preciso objetivo ni se aplica sólo en relación con él.

2. Un tema de actualidad: la semana laboral de 35 horas

Para comprender que estamos ante un tema de indudable actualidad basta recordar algunos hechos de notable eco en los últimos meses.

- Las victorias electorales del nuevo laborismo en Inglaterra (Tony Blair) y del socialismo en Francia (Lionel Jospin) se suceden con intervalo de un mes (1 de mayo y 1 de junio de 1997). A los pocos días ambos líderes proclaman la necesidad de una Europa social para acabar con el paro.

- En agosto del año pasado el gobierno francés lanza un plan de choque para emplear a 350.000 jóvenes.

- En octubre pasado se llega a un acuerdo en Italia entre la formación política del Olivo y Refundación Comunista para defender una ley que reduzca la jornada laboral a 35 horas semanales, acuerdo que provoca una fuerte reacción de la patronal.

- Por esos mismos días el gobierno socialista portugués anuncia que propondrá al Parlamento la semana de cuatro días para los funcionarios desde 1998, con carácter voluntario y reduciendo su salario en torno al $10 \%$.

- El 10 de diciembre de 1997 el gobierno francés aprueba el proyecto de ley que implanta la semana laboral de 35 horas. El proyecto fue aprobado definitivamente por la Asamblea francesa el 19 de mayo de este año, tras seis meses de dura pelea política y parlamentaria (3).

(3) El instituto de análisis coyuntural parisino OFCE ha valorado favorablemente la semana de 35 horas en Francia con la condición de que vaya acompañada de recortes salariales. Según este instituto en los tres primeros años se generarán unos 480.000 puestos de trabajo, siempre que la reducción de jornada a 35 horas vaya acompañada de una reducción de salarios al equivalente de 37'8 horas para todos salvo las personas peor remuneradas. 
- Durante estos mismos meses los sindicatos españoles han insistido en rebajar la jornada laboral desde las 39 horas, que es la media actual según convenios, hasta 35 horas, atreviéndose incluso a cifrar en 270.000 los nuevos empleos que esta medida crearía (4). La propuesta se hizo efectiva el pasado 10 de junio, indicando su disposición de acompañarla con una estrategia de moderación salarial.

- Más recientemente todavía la patronal de la Confederación Española de Cajas de Ahorros ha presentado una oferta de 35 horas en el 7\% de las oficinas a cambio de libertad de horario para abrir al público de 8.00 a 21.00 horas (más los sábados por la mañana). Los sindicatos han acogida con reservas la oferta y exigen un compromiso de creación de empleo. En todo caso, la incidencia de este recorte será relativa ya que la media actual está en 37 horas y además sólo se aplicaría al 7\% de las oficinas como hemos indicado anteriormente.

- Los partidos españoles de la oposición, principalmente PSOE e IU, se han manifestado a favor de este proyecto, si bien con propuestas diversas.

El enumerar estas distintas iniciativas y propuestas, todas localizadas en países de la UE, tiene un interés adicional. La creciente integración europea exige que estas modificaciones en las políticas de empleo se hagan de forma coordinada. Al consumarse la unión monetaria el tema del empleo ha quedado entre las competencias de los gobiernos nacionales. Pero ello no obsta para comprender que, por razones de competitividad, un Estado no puede actuar independientemente en un espacio geográfico tan integrado. Es de desear, por tanto, una progresiva coordinación en un campo como éste, donde el problema reviste una gravedad parecida en todos los países miembros.

Con todo, las iniciativas de los diferentes países marchan a distinto ritmo. La más avanzada, tanto por su alcance intrínseco cuanto porque

(4) En opinión de Antonio Gutiérrez, secretario general de CC.OO., «cuando hablamos de reducir la jornada semanal a 35 horas desde las 39 que hoy tenemos como media en los convenios colectivos, estamos hablando de la posibilidad de contribuir a crear un mínimo de 270.000 puestos de trabajo a jornada completa, en la visión más pesimista» (El País, 19 noviembre 1997, p. 60). 
además ha adquirido ya fuerza de ley, es la promovida en Francia por la Ministra de Trabajo y Solidaridad, Martine Aubry. Por esta razón nos detenemos a exponer sus extremos más relevantes:

a) La jornada semanal será de 35 horas a partir del año 2000 para las empresas de más de 20 trabajadores y a partir del año 2002 para las restantes.

b) La aplicación de esta medida será objeto de negociación en cada empresa, permitiéndose que se utilice un cómputo anual, con tal que haya siempre creación de empleo.

c) Habrá ayudas de 9.000 francos por empleado (225.000 pesetas) para las empresas que reduzcan un $10 \%$ su jornada laboral y aumenten un 6\% su plantilla, que podrán elevarse a 13.000 francos si la reducción de jornada llega al $15 \%$ y la contratación se incrementa en un 9\%. Estos incentivos irán disminuyendo progresivamente en los años sucesivos.

d) Se admite una jornada superior a las 35 horas, pero el exceso se computará como horas extraordinarias, las cuales también quedan limitadas a 130 anuales para empresas de más de 10 trabajadores y penalizadas en su retribución.

e) Habrá otras ayudas para incentivar la contratación de jóvenes, de parados de larga duración y de minusválidos.

A diferencia de lo ocurrido en Francia, el gobierno español no se decide a dar ningún paso en esta línea. Basta analizar el reciente Plan Nacional de Acción por el Empleo, presentado públicamente el 2 de abril para cumplir con los compromisos asumidos en la mencionada Cumbre de Luxemburgo. A pesar de las presiones recibidas, las medidas se orientan en otras direcciones: incentivos a la contratación, principalmente estable, de colectivos en dificultades, territorialización de los servicios de empleo y seguimiento detallado de la situación de cada demandante de empleo. Los objetivos a conseguir se cifran en una reducción del número de parados del $15 \%$ en los próximos tres años y un crecimiento del empleo del $7 \%$. Nada se dice del reparto del trabajo: quizás ha parecido más prudente esperar para ver los resultados que se producen en Francia, antes de arriesgarnos a poner en práctica algo parecido en nuestro país.

Quien sí parece haber cambiado de postura recientemente ha sido la 
OCDE, que también ha querido sumarse al debate sobre las 35 horas en Europa. En su último informe Perspectivas del empleo 1998 reconoce, por primera vez, que la reducción de la jornada laboral puede crear empleo, siempre que vaya acompañada de flexibilidad laboral y de moderación salarial.

\section{La reducción del tiempo de trabajo y la lucha contra el paro}

Hace pocos años tuvo un cierto éxito la fórmula «Trabajar menos para trabajar todos», que sirvió de título a un libro de Guy Aznar publicado en Francia y traducido pronto al castellano. El mensaje lo entiende todo el mundo como expresión inequívoca de redistribución del trabajo. En términos matemáticos podría decirse: por cada siete personas que reduzcan su jornada semanal de 40 a 35 horas se podría crear un puesto de trabajo más (el mismo tiempo de trabajo total, 280 horas, puede distribuirse entre 7 jornadas de 40 horas o entre 8 jornadas de 35 horas).

Pero esta regla de tres, que resulta tan fácil de entender, presenta no pocas dificultades cuando se quiere aplicar en la práctica. Hay dificultades que proceden de la misma realidad del trabajo: la principal es que la cantidad total de trabajo de una empresa o de la sociedad no es un todo que se pueda dividir de forma indefinida para repartirlo entre el número de personas que interese en cada momento. Y hay dificultades que proceden de las disposiciones de los afectados: ¿estarán dispuestos los trabajadores a aceptar esa reducción, sobre todo cuando fuera acompañada de una disminución equivalente de los ingresos? No son esos dos los únicos obstáculos para que funcione la fórmula de redistribución propuesta, pero dan una idea de la distancia que separa, en este caso, como casi siempre, la teoría de la práctica.

\section{De la historia al presente}

Históricamente la reducción del tiempo de trabajo se planteó de forma nada pacífica cuando el acelerado proceso de mecanización se traducía en una caída significativa de las necesidades de mano de obra. Hace ya siglo y medio los obreros llegaron a asaltar las fábricas al grito de «;Abajo 
las máquinas!» y a destruir los instrumentos de producción. Algunos llegaron a pronosticar el fin del trabajo. Sin duda se equivocaron, porque no contaron con la capacidad de creación de puestos de trabajo en otros sectores o líneas de producción. Sin embargo, parece que la evolución del empleo en las últimas décadas vuelve a desatar la polémica sobre el fin del trabajo.

Pero el avance tecnológico y la mecanización no sólo derivó en apertura de nuevas líneas de producción, sino en una reducción importante del tiempo de trabajo. El dato histórico es incontrovertible: en los países industrializados, en los últimos 120 años el tiempo de trabajo se ha reducido a la mitad, mientras que los ingresos se han multiplicado por 9 ó 10.

Tal reducción se ha plasmado de formas diversas: reducción de la semana laboral, alargamiento de las vacaciones, acortamiento de la vida profesional (por incorporación más tardía al mercado de trabajo y/o por salida más temprana del mismo), etc. Pero el resultado siempre va en la misma línea: el tiempo de su vida que el ser humano dedica a trabajar ha ido decreciendo de manera constante. Por tanto, ¿qué sentido tiene alarmarse ante una propuesta que encaja en una dinámica histórica de más de un siglo?

Ahora bien, por muy irrebatible que sea este dato, hay que ser cautos al sacar conclusiones de él. Porque el motor de ese proceso secular ha sido el incremento de la productividad, gracias al aumento de la inversión, a los avances tecnológicos y a las mejoras en la organización del trabajo. Ese proceso ha sido además impulsado por las luchas obreras y sindicales en reivindicación de mejores condiciones de trabajo. La acción concertada de todos estos factores se ha traducido, a la vez, en reducción del tiempo trabajado y en aumento de la retribución.

Toda esa experiencia está cargada de lecciones que sería insensato ignorar hoy. Pero, de momento, nos interesa más subrayar ciertas diferencias sustanciales entre ese pasado y nuestro presente. En primer lugar, ese proceso ha producido efectos perceptibles a largo plazo, mientras que hoy parecen cifrarse esperanzas en él a más corto plazo; pero, sobre todo, apremiados por la realidad intolerable de nuestro desempleo, la reducción del tiempo de trabajo no se plantea como la consecuencia del aumento de 
la productividad, sino como instrumento para aumentar el número de personas ocupadas.

Estos cambios, que parecen irrelevantes a primera vista, tienen efectos decisivos que obligan a analizar con más detención el comportamiento de las variables citadas, así como de otras que vamos a identificar en seguida.

\section{Las variables en juego}

Todo modelo que pretenda explicar un fenómeno social se encuentra con el espinoso problema de seleccionar las variables más significativas, procurando no olvidar ninguna que tenga una influencia determinante sobre la realidad y sus cambios. Eso ocurre cuando nos enfrentamos con el proceso histórico de reducción del tiempo de trabajo con una perspectiva dinámica: esta variable entra en interrelación recíproca con otras muchas. No es nuestra intención proponer modelos econométricos, hoy tan de moda. Más modestamente nos limitaremos a ofrecer una panorámica que permita identificar las variables más importantes y poner de relieve los posibles vínculos entre ellas.

Comenzaremos por el modelo más sencillo. Las tres variables que se tienen en cuenta de forma más inmediata, por sus relaciones recíprocas evidentes, son: la jornada laboral, la productividad y el salario. Suponiendo que todas las demás variables permanecen constantes y no reaccionan a la variación de estas tres, cabe decir: la disminución de la jornada con productividad constante podría hacer aumentar el empleo, pero siempre que se aceptara una disminución de los salarios proporcional a la reducción de la jornada; en este caso el tiempo total de trabajo sería el mismo y la producción global tampoco variaría, pero sí aumentaría la población ocupada. Ahora bien, si la reducción de jornada fuese acompañada de un aumento de la productividad, los salarios podrían mantenerse constantes, pero el tiempo de trabajo total sería menor y la población ocupada no variaría para una producción global invariada también.

Naturalmente este modelo es excesivamente simplificador... Aunque no llega a explicar lo que ocurre en la realidad, sirve como punto de partida. Introduzcamos para complicarlo tres variables más: los costes laborales de la empresa, las horas extra y el crecimiento económico global. En 
opinión de muchos, que la ilustran con diferentes estudios empíricos, la reducción de tiempo de trabajo no produciría los efectos deseados sobre el empleo debido a la reacción de estas tres nuevas variables. Por una parte, aun cuando los salarios disminuyan proporcionalmente, los costes laborales tienden a crecer debido al incremento de los costes laborales no salariales. Esta razón lleva a la empresa a preferir cubrir las horas liberadas con horas extra: pueden ser proporcionalmente más baratas y permiten no tener que recurrir a nuevas contrataciones: sólo se recurriría a éstas cuando el tiempo de trabajo se reduce en forma muy considerable, cosa difícil de concebir. Por último, y según el parecer de algunos, la reducción del tiempo de trabajo no fomenta el crecimiento económico, sino que es más bien una rémora para éste: sobre todo la caída de los salarios genera una disminución del poder de compra, cosa que dificulta por su parte la creación de empleo.

En una economía con fuerte presencia pública no es posible ignorar la interacción de la variable empleo con el gasto público y los ingresos públicos. La creación de empleo puede redundar en una reducción de los gastos sociales como consecuencia de la previsible disminución de los subsidios de desempleo. Algunos economistas proponen orientar este ahorro público, o una parte de él, a incentivar los nuevos puestos de trabajo, mediante ayuda de diferentes tipos, cosa que en principio parece preferible a la creación directa de empleo. Los efectos de la creación de empleo sobre los ingresos públicos podrían ser positivos siempre que aumente la producción y la renta global, pero hemos visto que tal efecto no se producirá de forma mecánica.

Hasta ahora hemos procedido en nuestro razonamiento sin atender a otras dos variables: la utilización del equipo de capital y la organización del trabajo. Dicho de otro modo: hemos supuesto que estos cambios no inciden sobre el grado de utilización del capital y sobre la forma de organizar el trabajo. Pero aquí la historia ya mencionada de la reducción del tiempo de trabajo ofrece datos ilustrativos sobre la contribución de estas dos variables a la mejora de la productividad. Por una parte, la reducción del tiempo de trabajo ha ido acompañada de una utilización más intensiva de los equipos productivos, esencialmente gracias a la introducción de turnos de trabajo. Con todo, el fenómeno más interesante de todo 
este período de más de un siglo ha sido la progresiva reorganización del trabajo, en sus múltiples facetas, desde la fragmentación de las tareas y los tiempos (siempre que ello sea posible) hasta formas organizativas que responden al concepto más moderno de flexibilización. El interés que ésta despierta hoy es innegable, hasta el punto de no faltar nunca en las negociaciones colectivas a cualquier nivel ni en cualquier propuesta de política laboral. Dicho interés no está reñido, sin embargo, con una cierta ambivalencia. Siendo un objetivo atractivo tanto para los trabajadores como para las empresas, unos y otras lo persiguen por razones distintas y desde valoraciones diferentes: para los primeros es, esencialmente, una expresión de soberanía sobre el tiempo; las empresas ven más bien en ella un instrumento de defensa frente a la incertidumbre y un medio de adaptación a un mercado sometido a rápidos cambios. En todo caso, la flexibilización laboral mantiene vínculos estrechos con las otras variables que venimos considerando (jornada de trabajo, productividad...), ya que elimina importantes rigideces en la gestión del tiempo de trabajo.

Cualquier afirmación que se haga sobre la reducción del tiempo de trabajo debe todavía someterse a matizaciones importantes atendiendo a la variable dimensión de la empresa. Es indudable que esa gestión más flexible del trabajo encuentra mejores oportunidades en las grandes empresas que en las pequeñas. Este dato pondría sordina a un excesivo optimismo, porque las PYME (considerando como tales las empresas de menos de 250 trabajadores) suponen el 68\% del empleo en España, pero las más pequeñas (menos de 10 trabajadores) responden del $43 \%$ del empleo. Pero también habría que tener en cuenta que las posibilidades de flexibilización del trabajo dependen, no sólo del tamaño de la empresa, sino también de las tareas concretas que cada una realiza y del modo cómo se organiza el trabajo.

Por último es obligado aludir a la variable pública-privada. Lo que está en juego aquí es la valoración que se haga de la productividad. La competitividad, que es un imperativo ineludible para la empresa privada, impone a ésta una atención muy esmerada a los cambios en la productividad, y por tanto a los efectos que tenga sobre ésta la reducción del tiempo de trabajo. Pero en el sector público se es menos sensible a la productividad porque se actúa sin el control de la competencia. Sería deplorable que 
la reducción del tiempo de trabajo se planteara, única o prioritariamente, en las administraciones públicas y sin reparar en sus efectos sobre la productividad, ya que ese precio terminaría siendo pagado por los presupuestos del Estado y, en último término, por todos los ciudadanos.

3. ¿Es posible cuantificar la incidencia de estas variables?

Aunque no pretendemos ser exhaustivos, las consideraciones precedentes no permiten dudar sobre la abundancia de variables en juego y la complejidad de las interrelaciones recíprocas. Mucho de lo que se escribe $y$, sobre todo, de lo que se dice en los medios de comunicación y en ciertos debates públicos, peca de simplificación. Porque es fácil seleccionar algunas variables para llegar a ciertas conclusiones, las que previamente se desean defender. Pero no es ésa la mejor vía para dotar al debate de una objetividad mínima.

Es normal que cada uno tenga una postura previa, ya sea en favor ya en contra de la reducción del tiempo de trabajo. Pero no sería honesto ignorar cuán difícil es encontrar un apoyo científico irrebatible a una u otra postura. Y no es que falten estudios que se ocupan de analizar las posibles o probables interrelaciones de estas variables. Ahora bien, ni los estudios teóricos ni los empíricos llegan a conclusiones indiscutibles. Más bien la modestia de éstas contrasta con la contundencia de afirmaciones y propuestas hechas en el debate político o sindical.

Algo se puede, sin embargo, decir en este marco de modestia. Tal como se ha indicado anteriormente, en pura lógica, la reducción de jornada debe ir unida -de una u otra forma- a un descenso de salarios, a un aumento de la productividad o a una combinación de ambos. El decremento de la jornada laboral parece exigir por lo tanto un descenso de los sueldos, que debería realizarse de forma gradual, y no de una sola vez, para que pueda ser compensado con incrementos de productividad. Aunque es posible adoptar medidas que puedan elevar los incrementos de productividad, tanto desde las administraciones públicas como desde las propias empresas, sus efectos no pueden ser ni rápidos ni muy amplios.

A través de los convenios se podría contar con que el «sacrificio» recayera parcialmente en la empresa, pero esta aportación no podría ser 
muy importante, dada la elevada competitividad que existe en los mercados en la actualidad. La aportación de la empresa a esta propuesta iría principalmente en la aceptación del riesgo e incertidumbre que comporta y en la organización del trabajo más adecuada a esta nueva situación.

El aumento del empleo sólo se puede alcanzar a medio plazo, dado que la adaptación de la empresa a la nueva jornada requiere cierto tiempo. Este proceso podría ser más rápido y más amplio si existen ayudas públicas a los aumentos de plantilla.

Desde el punto de vista macroeconómico hay varios factores que podrían influir de forma positiva: a) aumento del consumo nacional como resultado del incremento del empleo; b) aumento de la formación de capital por parte de aquellas empresas que tratan de compensar la menor jornada de trabajo con una mayor capitalización; en este fenómeno existe un efecto positivo y otro negativo sobre el empleo, pero a medio plazo el saldo puede ser favorable; y c) aumento de las exportaciones, que sólo sería posible cuando esta política de reducción de la jornada se adoptara de forma coordinada por los países de la UE.

Estos efectos globales son factibles en una etapa de crecimiento como la actual, lo que significa que ahora podría ser el momento de llevar adelante este proyecto, el cual sería inviable en una etapa recesiva.

En resumen, la reducción de la jornada de trabajo requiere sacrificios en el corto plazo, mientras que el aumento de empleo tendría lugar en el medio plazo.

En nuestra opinión la reducción del tiempo de trabajo beneficia al empleo, aunque dentro de un cierto margen de incertidumbre. Hay que insistir, sin embargo, en que su viabilidad depende de un cierto grado de solidaridad de las partes implicadas: trabajadores, empresarios y gobierno, solidaridad que debería estar presente en los acuerdos o convenios que se han citado en un párrafo anterior.

4. De la teoría a la práctica y a la negociación

Estas conclusiones, lejos de abonar un escepticismo paralizante, deben ser un estímulo para la búsqueda de combinaciones que sean beneficiosas. Las posibilidades teóricas son casi infinitas. En la práctica todo depende 
de la voluntad para negociar y de las disposiciones para ello. Lo importante es tener claro que son diferentes los intereses en juego y que en la negociación todos deben ser conjugados: los de los trabajadores, los de las empresas, los de la sociedad en general; pero, por encima de todos, los de los más afectados: los que no tienen trabajo.

Esta vía nos parece preferible a la estrictamente legislativa, aunque éste último haya sido el camino adoptado por Francia. Pero nótese que, aun en la ley francesa, se da un protagonismo importante a la negociación social, como queriendo decirse que, sin la colaboración activa de los agentes sociales, no son posibles, en éste como en casi todos los campos, avances considerables en el bienestar de todos. Ya pasó el tiempo en que teníamos una fe ciega en el estado providente, hasta el punto de ser tenido casi por omnipotente.

Cuando la negociación se emprende con voluntad y con espíritu creativo, la experiencia demuestra que las posibilidades se multiplican. Un ejemplo típico de cómo se pueden encontrar fórmulas complejas que satisfagan a todos lo tenemos en el tema tan frecuentemente debatido -al que ya hemos hecho alusión- de la reducción de salarios en relación con la reducción de jornada. Las propuestas más maximalistas se sitúan en los extremos: desde ciertas posturas empresariales, se exige sin más una reducción salarial proporcional a la disminución de jornada; desde algunas posiciones del mundo del trabajo se exige que la reducción de jornada por motivos redistributivos se haga manteniendo intactos los salarios. La negociación ha permitido encontrar salidas más aceptables. Se habla así de un salario compensatorio, resultado de recortar el salario, pero en proporción inferior a la reducción de jornada. A ello se une el compromiso de las empresas de no reducir el tiempo de trabajo global. Y, cuando la negociación se hace a tres bandas, los poderes públicos se comprometen a incentivar la creación de empleo con el ahorro proveniente de los subsidios de desempleo que desaparecen. Más aún, estudios empíricos muestran que el aumento de productividad neutraliza pronto el coste suplementario de ese salario compensatorio. Se trata, por tanto, de combinar los distintos elementos a que hemos hecho alusión, haciendo entrar en consideración una variable fundamental: el tiempo.

Todavía cabe añadir que el recorte de la retribución laboral admite 
también ciertos matices. Desde un punto de vista ético, habría que invocar aquí aquel principio del sacrificio igual que se aplica para justificar la progresividad impositiva. Reducir el salario es una renuncia que se pide a todas las personas ocupadas, con la intención de dar entrada a los excluidos del mercado laboral. Ahora bien, el sacrificio que dicha renuncia supone para los distintos niveles de ingresos no es en absoluto equiparable. Y esta circunstancia debería aplicarse a la hora de determinar qué recorte se establece para cada salario. En los extremos habría que afirmar que existen salarios, los más bajos, que no deberían nunca ser reducidos porque apenas permiten cubrir las necesidades vitales mínimas de sus perceptores, mientras que sería deseable, al menos en algunos casos y de forma transitoria, la congelación de los salarios más altos. Reducir no debe significar necesariamente bajar los sueldos, sino que bastaría con congelarlos y renunciar durante cierto tiempo a las subidas salariales que pretenden compensar la pérdida de capacidad adquisitiva por los efectos de la inflación. Este sería el sacrificio que se les exigiría a algunos de los trabajadores empleados, y a través del mismo mostrarían su solidaridad con los ciudadanos sin empleo.

\section{Otras formas de reparto del trabajo}

La reducción del tiempo de trabajo no es la única forma de repartir éste, aunque sea la más comúnmente planteada y discutida. En este apartado queremos pasar revista, de forma más somera, a algunas otras. Hemos seleccionado cinco: el trabajo a tiempo parcial, el puesto de trabajo compartido, la jubilación anticipada, los contratos de sustitución, las licencias de larga duración. En realidad no son modalidades independientes, algunas de ellas se aplican a veces de forma simultánea. Pero en el análisis nos ha parecido mejor distinguirlas, buscando en cada caso -de acuerdo con el enfoque de estas páginas- sus posibles efectos sobre el empleo.

\section{El trabajo a tiempo parcial}

El entender la jornada laboral como jornada completa es un factor más de rigidez en el mercado de trabajo. Pero durante mucho tiempo ha sido 
un ideal casi incuestionable, a pesar de que no siempre es lo mejor ni para el trabajador ni para la empresa. Hoy, sin embargo, se es mucho más escéptico ante esa postura tan maximalista. De hecho, el trabajo a tiempo parcial está bastante extendido en algunos países industrializados. En España representa sólo el $8 \%$ del empleo total, pero la media de la UE es el doble (un 16\%). En el Reino Unido alcanza ya el 24\% y en Holanda, el país donde más difundido está, llega al 38\%. No es aventurado, por consiguiente, ver en él un camino con posibilidades. Además la posibilidad de una jornada más reducida no es sólo una exigencia de flexibilidad por parte de la empresa, sino también una aspiración de muchos trabajadores. Puede ser, sin ir más lejos, una alternativa atrayente para el hombre o la mujer durante los años en que tienen hijos que les exigen una dedicación más prolongada en el tiempo.

Sin embargo, la fórmula tropieza con ciertas dificultades, que en nuestro país se consideran como relevantes. La más importante es el hecho de que en la práctica no es raro que trabajo a tiempo parcial equivalga a trabajo precario y mal pagado. Los trabajadores que suscriben un contrato a tiempo parcial gozan de escasa protección social: el principal problema es la dificultad que existe para acceder a las prestaciones económicas de la Seguridad Social, fundamentalmente la de jubilación, ya que el periodo de cotización que se les exige es superior al que precisan los trabajadores a tiempo completo. Pero hay otra circunstancia, más grave aún si cabe, que explica el recelo de los sindicatos ante él: en muchas ocasiones constituye una fuente de fraude laboral. Son frecuentes las denuncias de que muchos contratos a tiempo parcial son tapaderas de jornadas de trabajo muy prolongadas y a veces casi indefinidas. Esta praxis no sólo reduce los costes laborales (sobre todo no salariales), sino que sirve también para amparar a los niveles de economía sumergida. Por todo ello es explicable que este contrato no goce de buena prensa.

¿Son estas circunstancias decisivas para oponerse a su difusión? Creemos que no, especialmente si adivinamos ahí un posible frente -no el único, ni el más decisivo- capaz de contribuir a reducir el desempleo. Es evidente que sus efectos sobre el empleo no se dejarán notar a corto plazo. Pero a largo representa un elemento más de reorganización del trabajo y del tiempo que se consagra a él. 


\section{El puesto de trabajo compartido}

Es una praxis más restringida, pero que en algunos países se aplica, aunque con éxito diferente. Consiste en dividir una colocación a tiempo completo entre dos o más personas, cada una de las cuales conserva todos los derechos y ventajas aparejados al puesto. Aunque es una modalidad de trabajo a tiempo parcial, añade a éste el hecho de compartir una tarea (en este sentido, es más rígido), pero reduce también esa precariedad que tantas veces se le achaca.

Sus ventajas son innegables, pero en ellas radican sus dificultades. Compartir tareas estimula la creatividad, pero exige un alto nivel de comunicación. Compartir responsabilidades, además, sólo es posible cuando los sujetos en cuestión no tienden a descargar las propias en los demás. Todo esto sugiere que esta fórmula exige un aprendizaje, casi un cambio de mentalidad, y eso es difícil de improvisar.

Esta es una razón más para admitir que el compartir el puesto de trabajo no redundará a corto plazo tampoco sobre el nivel de empleo, pero introducirá elementos aprovechables para una revisión a fondo de lo que significa trabajar, y especialmente trabajar con otros. ¿Qué duda cabe, por otra parte, que esta fórmula contribuye a flexibilizar positivamente el trabajo?

\section{La jubilación anticipada y el contrato de sustitución}

El contrato de sustitución es una fórmula que se aplica combinándola con la jubilación anticipada. La edad de jubilación también ha estado sometida a un proceso continuo de reducción, que contrasta con el aumento también continuo de la esperanza de vida. Esta doble circunstancia alarga considerablemente el tiempo de vida que no se dedica a trabajo remunerado. Y este cambio plantea no pocos problemas. Unos son de carácter económico: concretamente el crecimiento del volumen de pensiones que cargan sobre los presupuestos públicos, agravado por la reducción del porcentaje de población activa y ocupada. Igualmente graves son los problemas humanos: crece en muchos casos la marginación del jubilado, así como las dificultades para llenar el tiempo liberado del trabajo. Esta nueva situación invita a revisar la concepción del tiempo 
libre o de ocio, teniendo en cuenta que cada vez pierde más aquella función que tenía de recuperación de fuerzas para volver a trabajar: su mayor autonomía permite enfocar su ocupación con fórmulas mucho más variadas y ricas. Es un tema que nos desviaría de nuestro objetivo en estas páginas, pero que no queremos dejar de mencionar, aunque sea de pasada, llamando la atención sobre las posibilidades que se abren aquí para un futuro que quizás no está tan lejos como muchos piensan.

Pero volviendo a la jubilación anticipada, es un hecho que muchas empresas han echado mano de ella para aligerar su personal, urgidas por los imperativos de la competencia y del desarrollo tecnológico. Ahora bien, el enfoque que se propone aquí es otro: ahora se pretende no eliminar mano de obra sobrante, sino reducir el desempleo. Y ello exige que el puesto que deja el que se jubila sea ocupado por un parado: en eso consiste el contrato de sustitución. De nuevo aquí puede actuar el estado con incentivos económicos que reduzcan los costes de la jubilación o de la nueva contratación.

Más aún, puede imaginarse el caso de que la sustitución sea progresiva, con lo que estamos en el supuesto ya analizado del puesto de trabajo compartido. Pero con algunas ventajas nuevas. La más digna de atención consiste en que la jubilación se hace de forma más suave, evitando el contraste tan acusado entre la jornada laboral normal y el abandono completo del trabajo. Especialmente cuando la jubilación se anticipa, la persona afectada suele estar todavía en muy buenas condiciones para desempeñar una actividad, tan útil para la empresa y la sociedad como gratificante para sí misma. Además, cabría pensar, aunque no siempre sea factible, que la coincidencia en el puesto laboral por un tiempo beneficiará a la persona que accede a él con la experiencia de la que se retira.

\section{Las licencias de larga duración}

He aquí otra fórmula que se practica con distintas modalidades, y de la que muchos se preguntan su efecto sobre el nivel de empleo. Entre ellas suelen citarse: los permisos sabáticos remunerados como recompensa por los servicios prestados (que se conceden a empleados de una cierta antigüedad), las licencias no remuneradas (excedencias, unidas muchas 
veces a reciclaje profesional), los mecanismos de «tiempo ahorrado» (se va acumulando tiempo, que luego se puede convertir en tiempo de no trabajo, lo que constituye una especie de retribución normal o extraordinaria que se hace, no en dinero, sino en tiempo libre).

$\mathrm{Su}$ efecto directo sobre el nivel de empleo no parece significativo. Indirectamente, en cambio, tiene su incidencia, sobre todo cuando permite al que lo disfruta dedicar un tiempo a la puesta al día. Y no hay que entender esta posibilidad como algo marginal, sólo practicado por pocos. En ella se insinúa otro cambio significativo en la forma de entender el trabajo y su relación con el tiempo de estudio. Tradicionalmente el tiempo de estudio precedía al tiempo de trabajo: lo normal era concluir los estudios antes de entrar en el mercado laboral. En el reciente Informe a la UNESCO sobre la educación en el siglo XXI (5) se defiende que, en un mundo en rápido proceso de cambio, es preciso plantearse la educación a lo largo de la vida. Esto implica el final de la división tradicional de la existencia en períodos claramente separados (infancia y juventud para la educación; edad adulta para la actividad profesional; periodo de jubilación): así lo exige el progreso acelerado de las ciencias, las dificultades del mercado de trabajo, la reducción de volumen total de horas de trabajo remunerado, el aumento de la esperanza de vida.

\section{Conclusión}

No es fácil concluir estas reflexiones. Pero hemos ido salpicando las páginas que preceden de tomas de postura en cuestiones debatidas, procurando también justificarlas con argumentos razonables (nunca apodícticos). Ahora queremos sintetizarlas a modo de conclusión.

1. Evidentemente estamos ante un problema grave: no sólo por las dimensiones cuantitativas del paro, sino por su carácter estructural, por los colectivos más duramente castigados por él y por sus efectos sociológicos y psicológicos que inciden sobre la cultura y los hábitos

(5) La educación encierra un tesoro. Informe a la UNESCO de la Comisión Internacional sobre la educación para el siglo XXI, presidida por JACQUES DELORS. Santillana - Ediciones UNESCO, Madrid 1996. 
dominantes en nuestras sociedades desarrolladas.

2. La lucha contra el paro no es tarea fácil. Exige estrategias diversificadas que ataquen al problema por diferentes flancos: cuantos más, mejor. No hay una solución «talismán». Las diferentes iniciativas serán tanto más eficaces cuanto más coherentes entre sí sean y más coordinadas estén.

3. La responsabilidad de la lucha contra el desempleo no puede descargarse sobre los poderes públicos: reside en la sociedad toda, y especialmente en los agentes sociales, protagonistas de la actividad económica. Esta lucha debe venir inspirada por los principios de la solidaridad (es un problema de todos, que todos deben afrontar) y de la creatividad (no vale refugiarse en las inercias del pasado, o en pretendidas metas ya conseguidas e innegociables). De ahí ha de seguirse una actitud negociadora, donde todos han de estar dispuestos a algún sacrificio, para empeñarse en la búsqueda de alternativas en las que todos aporten y todos obtengan algún beneficio.

4. Una alternativa en la que todo eso puede ponerse en juego es el reparto de trabajo. Las conclusiones de los estudios, tanto teóricos como empíricos, no son concluyentes en cuanto a sus efectos sobre el empleo. El reparto de trabajo no se traduce automáticamente en mejora del empleo global. Pero ello es una razón, no para renunciar a esta medida, sino para acompañarla de otras que permitan el acceso al trabajo de personas en paro.

5. En los últimos años se han barajado diferentes fórmulas que pueden conducir, directa o indirectamente, al reparto de trabajo. La reducción del tiempo de trabajo es la más importante; pero debe añadirse otras como: el trabajo a tiempo parcial, el puesto de trabajo compartido, la jubilación anticipada, los contratos de sustitución, las licencias de larga duración. Unas son antiguas, aunque no siempre se aplicaron con esta finalidad; otras son más recientes y han nacido en el contexto de la lucha por el empleo. Tal pluralidad ha de reconocerse como una riqueza y muestra cómo surgen posibilidades inéditas siempre que se rompe con inercias del pasado, aunque las fórmulas ideadas no resulten satisfactorias al cien por cien desde el primer momento.

6. Puesto que el trabajo es vía de acceso a la renta, el reparto de aquél 
implica de algún modo reparto de ésta. Es imposible eludir esta cuestión, que se plantea de forma aguda en el caso de reducción de la jornada de trabajo. De entrada hay que afirmar que es impensable repartir el trabajo sin repartir la renta. Esta ha de ser disposición elemental de todo colectivo abocado a negociar una reducción del tiempo de trabajo. Pero tampoco hay que entender este recorte de forma drástica (estrictamente proporcional) y sin contrapartida: por una parte, existe siempre una compensación en términos de aumento del tiempo de ocio; además, no tiene por qué ser estrictamente proporcional la disminución del trabajo y la de la renta; por último, la pérdida tiende a recuperarse al cabo de cierto tiempo. Todo esto se hará realidad en la medida en que las actitudes de las partes sean abiertas al cambio y flexibles a una negociación en que se busca que nadie resulte perdedor en términos absolutos.

7. Todo lo dicho sobre lucha contra el desempleo a través del reparto del trabajo en una época de paro estructural debe entenderse en el marco de un proceso siempre abierto. Esto significa que el paradigma del trabajo en la sociedad y en la cultura industrial no es definitivo (tampoco tiene muchos años de vida...) y está en permanente evolución. Las dimensiones de la jornada laboral en nuestras sociedades están planteando ya una nueva relación entre trabajo y ocio y abre nuevas posibilidades al tiempo de no trabajo, que afectarán cada vez más a toda la organización de la vida y a la cultura toda. Por otro lado, el reparto del tiempo de trabajo debería servir no sólo para combatir el desempleo sino para crear un nuevo modelo de sociedad en donde hombres y mujeres tengan cabida; un modelo socioeconómico al servicio de las personas y no a la inversa; un modelo que no excluya a los «improductivos» (discapacitados, ancianos...), que reconozca el valor que el trabajo llamado «reproductivo» (atención de los hijos, hogar y mayores) tiene en la transmisión de valores en la sociedad; un modelo que acabe con el despilfarro del Norte que condena a la miseria al Sur. Este es un tema que escapa al análisis de este editorial. Dejarlo abierto al concluir estas páginas quiere ser expresión de nuestra fe en el progreso de la historia que, si es solidaria y responsablemente asumida por todos, redundará también en un mundo más humano y justo para todos. 